\title{
La República de las mujeres
}

\author{
Rosario Ruiz Franco \\ Universidad Carlos III de Madrid \\ Women's Republic
}

\begin{abstract}
RESUMEN ABSTRACT
Este estudio analiza la visión política y la In this paper we analyze the politic vision ideología republicana de un grupo de intelectuales, políticas y abogadas españolas de la España de los años treinta. Igualmente se estudia la interpretación de la II República desde el punto de vista femenino así como las ventajas que en su opinión ofrecía el régimen republicano frente a la monarquía.

PALABRAS CLAVE: Mujeres; II República; Ideología política; and the republican ideology of a group of intellectuals, policies and spanish lawyers of the thirties. Also we study the interpretation of the second Republic from the feminine point of view as well as the advantages that in their opinion the republican regime offered against monarchy.

KEYWORDS:

Women; Republic II; Politic ideology; Spain
\end{abstract} España

\section{INTRODUCCIÓN}

Con el advenimiento de la II República muchos españoles esperaban ver realizados sus sueños de libertad, justicia e igualdad. Entre ellos, las mujeres, tal vez, era el grupo social que más esperanzas tenían depositadas en él, y a las que a su vez más se las animaba a participar consciente y activamente en el desarrollo del mismo. El presente estudio tiene como objetivo profundizar en un grupo de mujeres con ideario republicano para analizar su visión de la República, su interpretación de la misma desde el punto de vista femenino así como las ventajas que en su opinión ofrecía el régimen republicano frente a la Monarquía. Nos centraremos en 
las aportaciones de intelectuales, políticas y abogadas como Carmen de Burgos, María Lejárraga (Martínez Sierra), Clara Campoamor, Victoria Kent, Margarita Nelken, María Zambrano o Concha Peña, entre otras.

\section{2. «REPÚBLICA, REPÚBLICA SIEMPRE!»}

En abril de 1931 era evidente que la monarquía de Alfonso XIII no había sabido resolver los múltiples problemas existentes en España. Igualmente palpable era la falta de apoyo del pueblo, de gran parte de la clase política y de los intelectuales. La II República alcanzó el poder a través de unas elecciones municipales, de forma pacífica sin la utilización de la violencia, y empujada por el entusiasmo de aquellos hombres y mujeres que confiaban en mejorar la situación de atraso y penuria reinante en España en distintos órdenes.

En lo que se refiere a las relaciones de género, no se puede decir que en 1931 el nivel cultural, laboral y político de las mujeres en España fuera óptimo, que el ambiente fuera del todo favorable para reivindicar cuestiones de derechos o emancipación social de las mujeres, que el feminismo español tuviera excesiva fuerza, ni que fuera prioridad del nuevo régimen; pero la oportunidad y las condiciones sociopolíticas se presentaban y había que aprovecharlas. En su contra, esta lucha tenía importantes adversarios como era el peso de la tradición, la educación, el papel diferenciado de los sexos en la sociedad, la influencia conservadora de la Iglesia, y el escaso interés de los partidos más progresistas, más allá de lo estrictamente político. A todo ello se suma que en el ámbito internacional las reivindicaciones feministas españolas iban contracorriente, ya que la década de los años treinta se caracteriza por un reflujo en el feminismo y un culto a la feminidad en países como la Unión Soviética, Italia, Alemania o Estados Unidos. En este contexto histórico debemos enmarcar la actuación del grupo de mujeres objeto de nuestro interés, que desde la década de los años veinte y muy especialmente a comienzos de los años treinta, van a llevar a cabo una importante labor de concienciación política republicana y de defensa de los derechos de las mujeres.

La proclamación de la II República en abril de 1931 fue muy bien recibida por muchas mujeres. En palabras de María Lejárraga «su advenimiento me proporcionó la mayor alegría de mi vida (...) el 14 de abril creí rejuvenecer y me lancé a la calle para presenciar entusiasmada la eclosión del pueblo"'. Todas ellas fueron partícipes de la alegría que recorría las ciudades y pueblos de España durante la jornada del día 14 de abril. La escritora María Zambrano en su obra Delirio y Destino recuerda con especial atención esas horas vividas en la ciudad de Madrid, la alegría del pueblo, la presencia de cantos y banderas republicanas por las calles de la capital, la salida de los monarcas hacia el exilio, la actuación pacífica y responsable de los ciudadanos: «En la Puerta del Sol los grupos se renovaban ince-

1 Martínez Olmedilla, A.: «El día de María Martinez Sierra». ABC, 13-IX-1931, pág. 6. 
santemente, como si la ciudad toda hubiese de pasar por aquel lugar, por aquel Centro Mágico. Bajando por un costado de Gobernación llegó un grupo de obreros como danzando. Uno de los que formaba el grupo se destacó dirigiéndose a alguien que pasaba y gritó: « $i$ Viva la República!», mientras los demás revoloteaban en su danza improvisada, « $V i v a$ España!», y alzando el puño , en un comienzo de ira con voz un poco ronca: " $\uparrow$ Y muera!... pero no, que no muera nadie, que viva todo el mundo. Sí, viva el Mundo, que vivan todos, todo el mundo"»"2

Algunas de estas mujeres republicanas habían tenido una participación destacada vísperas del decisivo acontecimiento político, tal es el caso de Victoria Kent o Clara Campoamor quienes habían defendido a algunos de los republicanos implicados en la intentona revolucionaria de 1930. Una vez proclamada la República muchas de ellas ocuparon, además, cargos de representación política como diputadas, véase Victoria Kent, Clara Campoamor, Margarita Nelken o María Lejárraga o de responsabilidad pública, tal es el caso de Victoria Kent como Directora General de Prisiones o Clara Campoamor como miembro de la Comisión de Constitución de las Cortes españolas, Directora General de Beneficencia, y representante del gobierno republicano ante la Sociedad de Naciones. Su compromiso republicano se materializa también con un compromiso político, con la militancia en partidos republicanos por entender que es la vía para conseguir los fines perseguidos. Carmen de Burgos y Victoria Kent estuvieron afiliadas al Partido Republicano Radical Socialista, Clara Campoamor y Concha Peña al Partido Radical, Margarita Nelken y María Lejárraga al Partido Socialista, y María Zambrano durante un breve periodo de tiempo a Alianza Republicana. Son mujeres que también se declaran defensoras de los derechos de las mujeres, algunas de ellas claramente feministas, y todas ellas van a trabajar para mejorar la situación de las mujeres en España durante esos años.

La visión que tienen estas mujeres de la República es una visión política optimista, constructiva, y llena de esperanza al considerar que el nuevo régimen vendrá a mejorar la situación de los españoles, a sacar a España del atraso, del hambre y de la ignorancia. La escritora Carmen de Burgos manifiesta su entusiasmo por el cambio de régimen, a la vez que solicita la implicación de los ciudadanos, tiempo y tranquilidad para poder llevar a cabo las transformaciones necesarias: “iAh; soy completamente optimista! Creo que el porvenir nos pertenece. Nuestra maravillosa jornada del 14 de abril, así lo hace esperar (...) Cuando se ha esperado durante mucho tiempo una cosa muy deseada, no debemos precipitarnos al conseguirla. Un pueblo no puede transformarse desde La Gaceta. La verdadera transformación, la radical, hemos de hacerla antes en nosotros mismos, proclamando la república en nuestros espíritus, en nuestros hogares, reformando, incluso, el vocabulario. Pero todo esto vendrá y los que pretendan iniciar campañas de retroceso no conseguirán más que impulsar hacia delante nuestro momento. No

${ }^{2}$ Zambrano, M.: Delirio y Destino (los veinte años de una española). Barcelona, Mondadori España, 1989, pp. 260-261. 
me parece que debamos acelerar demasiado este ritmo, pero siempre preferiré la velocidad revolucionaria al reaccionario vencido que no se resigna" ${ }^{3}$.

La República se presenta para estas mujeres como el régimen político más adecuado para regir un país. Clara Campoamor, preguntada por la disyuntiva entre República o Monarquía, se decanta claramente por la primera: «iRepública, república siempre!. Me parece la forma de gobierno más conforme con la evolución natural de los pueblos. Y en muchos casos, la más adecuada a la situación de un país especialmente considerado, verbigracia, España. Pero prescindiendo ya de este sentido oportunista, objetivamente me parece superior la república a cualquier otro régimen " ${ }^{4}$. Y también como el régimen político que va a solucionar los problemas que la Monarquía ha sido incapaz de resolver. En opinión de María Zambrano se presentaba como «inevitable», como la «solución única de un problema»: «Y ahora en aquel instante había que reconstruir la nación, recrearla. Y era ése el proceso creador que tenía lugar: la República era el vehículo, el régimen; la realidad era la Nación; la realidad se estaba recreando» ${ }^{5}$. Victoria Kent creía que era el régimen político que podía salvar a España. En una entrevista de Josefina Carabias a la pregunta de «¿Usted ha sido siempre republicana?», respondía "Siempre; pero, aunque hubiese sido monárquica o indiferente, habría comprendido que España no podía salvarse más que así»"

Por su parte, María Lejárraga preguntándose por la ineficacia de la Monarquía señalaba: "Yo ceo que el impulso que ha movido al poder irresponsable a mantener a España en tenaz marcha atrás, durante casi medio siglo, era sencillamente el pánico. No es que la monarquía que se acaba de hundir fuese esencialmente retrógrada. Es que cada paso hacia adelante se le antojaba un paso hacia el abismo».En su opinión el apoyo a la República se justificaba fundamentalmente por razones utilitaristas: «Toda la obra que ella no realizó en su afán de inmovilizar al país, para que la menor sacudida no hiciese vacilar el trono, toda esa labor, urgente y formidable, quieren llevarla a cabo los que hoy gobiernan ¿Quieren?¡Quieren y saben! ¡De eso respondo, porque sé quienes son! ¿Podrán? Si todos les ayudamos, ipueden! Y dejando aparte todo idealismo, y por encima de todo apasionamiento, harán lo que deben y lo que son capaces de hacer, porque les conviene hacerlo. La justificación de este cambio de régimen está en su utilidad. Si la República no remedia los males que existen, no tiene ella misma razón de existir»?.

3 Olmo, R.: «La mujer en la política. Carmen de Burgos». Mujer, 27 de junio de 1931, n. ${ }^{\circ}$ 4, p. 6.

${ }^{4}$ El Liberal, 22 de abril de 1930.

5 Zambrano, M.: Delirio y Destino (los veinte años de una española). Barcelona, Mondadori España, 1989, pp. 191, 192 y 198.

6 CARABIAS, J.: Crónicas de la República. Del optimismo de 1931 a las vísperas de la tragedia de 1936. Madrid, Temas de hoy, 1997, pág. 27.

7 Martínez Sierra, M.: La mujer española ante la República. Madrid, Ediciones de la Esfinge, 1931, pág. 55. 


\section{3. “LA REPÚBLICA, GRAN AMIGA DE LA MUJER»}

Sus esperanzas en el nuevo régimen también se plantean desde el punto de vista de las relaciones de género. Conscientes de la marginal situación de la mujer en España, estas mujeres muestran su confianza en que la República trabaje para mejorar su situación política, social y jurídica. Así lo manifestaba la abogada Concha Peña: «Estoy satisfecha del nuevo régimen: creo y espero mucho bueno de este Gobierno; al fin -suspira-me parece que hemos llegado a lo que desde niña vislumbre. Aparte de mis ideas políticas, que hoy tras muchas luchas y sinsabores veo realizadas, es un hecho ya la igualdad de la mujer en todos los órdenes ${ }^{8}$. Victoria Kent declaraba su entusiasmo y confianza en el régimen republicano a la periodista y abogada Josefina Carabias: «más que por mí por lo que representa para todas las mujeres españolas ${ }_{j} H e m o s$ vivido en un atraso tan lamentable! ... Afortunadamente, ya se ha roto el hielo. Las mujeres hemos trabajado por la República, y esté segura de que la República no ha de negarnos uno solo de los derechos que ya han conquistado las mujeres de todos los países"9.

Para conseguir estos objetivos instan a las mujeres a trabajar por y para la República, a implicarse en la política del nuevo régimen. María Lejárraga animaba a las mujeres de cualquier credo político y religioso a apoyar al nuevo gobierno: «el motivo primero, esencial, femenino y feminista que debe obligarnos a todas las mujeres españolas, monárquicas, liberales, progresistas, tradicionalistas, socialistas, católicas o librepensadoras, moras o cristianas, a apoyar al actual Gobierno de España, es que su programa, aunque todavía, inevitablemente, un poco idealista, es decir, un poco artificial, se acerca mucho más que cualquier otro, monárquico o imperialista, a la ley natural y realista, que es nuestro solo Código "10. Y también las alentaba a prepararse adecuadamente para esa conveniente colaboración con el gobierno republicano: «El Gobierno de la Buena Voluntad piensa en nosotras para que le ayudemos a gobernar la casa. Procuremos desde hoy capacitarnos para responder a su llamamiento. Estudie cada una su vocación, es decir, piense en el trabajo que más le agradaría realizar "11.

Como planteaba María Lejárraga era necesario contar con el apoyo y la colaboración de las mujeres para alcanzar los objetivos propuestos. A partir de ese momento se suceden conferencias, charlas, mítines, y se publican artículos, libros o revistas específicamente femeninas como Mujer en los que se informa de la situación política, de las posibilidades que la República puede ofrecer a las mujeres y se insta a su colaboración. Igualmente destacable es la labor llevada a cabo por las asociaciones de mujeres como Lyceum Club, Cruzada de Mujeres Españolas,

${ }^{8}$ Guitian, M.: «La mujer en la política. Concha Peña». Mujer, 22 de agosto de 1931, n. ${ }^{\circ}$ 12, pág. 5.

${ }^{9}$ Carabias, J.: Crónicas de la República. Del optimismo de 1931 a las vísperas de la tragedia de 1936. Madrid, Temas de hoy, 1997, pp. 26-27.

10 Martínez Sierra, M.: La mujer española ante la República. Madrid, Ediciones de la Esfinge, 1931, pág.17.

11 Idem, pág. 29. 
Federación Internacional de Mujeres Universitarias, Asociación Universitaria Femenina, y muy especialmente por las de mujeres republicanas como la Asociación de Mujeres Españolas, Unión Republicana Femenina, Agrupación Socialista Femenina o la Asociación Femenina de Educación Cívica, entre otras. Sus objetivos, principalmente, iban dirigidos a la preparación cultural, la educación cívica, y la igualdad laboral de las mujeres. La Unión Republicana Femenina nació con un propósito más específico. Fue creada en 1931 por Clara Campoamor con la intención de «laborar contra el ambiente adverso al voto» ${ }^{12}$. En palabras de Carmen de Burgos todas las iniciativas surgidas en esos años tenían el fin último de «llevar a las Cortes con toda energía unas peticiones en las que tratarán de concretarse lo que quiere la mujer de la República»’13.

En esta línea, en mayo de 1931 María Lejárraga impartió un curso de cinco conferencias en el Ateneo de Madrid. Posteriormente fueron recopiladas y publicadas bajo el título "La mujer española ante la República», un documento de gran valor histórico y que nos ayuda a profundizar en los aspectos aquí planteados. En la primera de ellas y bajo el título «Realidad» la escritora elogiaba la actitud y madurez política de los españoles ante la proclamación del nuevo régimen: «El pueblo ineducado, el pueblo ingobernable, el pueblo a quien se dejó dueño absoluto de las calles de la capital supo iluminar las tinieblas de su ignorancia, impuesta oficialmente, con la luz consciente y voluntaria de la razón. $Y$ en vez de destruir y vengarse al grito, para tantos temerosos, de ;Viva la República!, supo respetar todo lo respetable y perdonar todo lo aborrecido para clamar con júbilo « iViva España libre! ’ ${ }^{14}$.Igualmente solicitaba a las mujeres orden, vigilancia y muy espacialmente trabajo, dirigiendo duras críticas a las mujeres ociosas principalmente entre las clases privilegiadas: "civilización en que la mujer está ociosa, se corrompe inevitablemente. Porque el parásito, y parásito es todo el que se hace mantener sin dar trabajo en pago, destruye el organismo a costa del cual vive. A trabajar, pues, mujeres; a aprovechar el tiempo las que hasta hoy os habéis contentado con perderle o matarle» ${ }^{15}$.

Finalizaba su intervención instando a las mujeres a colaborar con el nuevo gobierno: «Nos hemos mantenido hasta hoy totalmente alejadas de la tarea, no tanto por carencia de derecho a intervenir, como por repulsión invencible. Estábamos tan convencidas de que todo era inútil y todo ineficaz, de que gobernación, administración de la hacienda pública, instrucción, fomento y riqueza nacional... ¿a qué seguir nombrando actividades gubernamentales?, eran, no diré farsas, por no ofender, pero sí absolutas irrealidades. Por primera vez ¿desde cuando, Señor?, está un maestro de escuela al frente del Ministerio de Instrucción Pública, un

12 Campoamor, C.: Mi pecado mortal. El voto femenino y yo. Sevilla, Instituto Andaluz de la Mujer, 2001, pág. 155

13 Olmo, R.: «La mujer en la política. Carmen de Burgos». Mujer, 27 de junio de 1931, n. ${ }^{\circ}$ 4, p. 6.

14 Martínez Sierra, M.: La mujer española ante la República. Madrid, Ediciones de la Esfinge, 1931, pág. 18.

15 Idem, pág. 27 
maestro en Derecho en el de Justicia, un hombre que entiende de números en el de Hacienda, otro que ha rodado por toda la tierra en el de Relaciones Exteriores...iRealidad, realidad, suprema aspiración femenina; realidad, hace tantos siglos ausente de la historia de España, sueño inalcanzable, la fin estás aquí y apenas lo podemos creer!. Mujeres españolas, cualquiera que sea nuestro credo político, estamos, indudablemente, de enhorabuena. Nuestro anhelo, que es el aliento mismo de la Vida, ha subido a regir los destinos de España. Alegrémonos, pues, sincera, profunda e imparcialmente. Pero manifestemos nuestro gozo, pagándole en esfuerzo. ¡A trabajar, hermanas, que obras son amores!»16.

En su segunda conferencia, «Egoísmo», trató sobre el deber de solidaridad en apoyo al nuevo régimen político y sus esfuerzos en distintos aspectos en materia cultural y educativa, animando nuevamente a la participación de las españolas: "iSeamos egoístas, mujeres! Exijamos la buena obra y ayudemos a realizarla. Para nosotras, la Patria son los hombres. Nuestros hijos, todos, que todos han nacido de mujer " ${ }^{17}$. En su opinión y de forma premonitoria, alertaba de que en caso de fomentar "el odio y la contradicción dentro de la Patria» podría desembocarse en una guerra civil: "No la encendáis a ciegas, mujeres de España!. Somos mayoría dentro de la Patria (..) Nuestra opinión decidirá este pleito: Paz o guerra civil» ${ }^{18}$. En su tercera conferencia, «Libertad», analizaba los artículos del Código civil vigente que situaban a las mujeres en un estado de minoría de edad permanente y dependiente del varón, y concluía señalando la conveniencia de mejorar la situación jurídica de las mujeres para los propios intereses del gobierno republicano: «Al Gobierno de la Buena Voluntad Española no le conviene tener esclavos a quienes temer ni descontentos a quien domeñar. También él necesita, para construir, tener las manos libres y el pensamiento sin preocupaciones. $Y$ esa libertad que él ha de menester, no la puede lograr sino con la que otorgue, que libertad se compra con libertad,como amor con amor ${ }^{19}$. No obstante mostraba su agradecimiento por la labor ya realizada hacia las mujeres y el abismo con la llevada a cabo durante la Monarquía: «En quince días, el Gobierno provisional de la República ha hecho más a favor de las mujeres que todos los Gobiernos monárquicos que se han sucedido desde el reinado del sabio Alfonso $X$ (...) $Y$ esto es sólo empezar. Porque de las Cortes Constituyentes saldrá la absoluta igualdad en derecho para hombres y mujeres. Ved si nos conviene que triunfe a la hora presente, en España, el voto favorable a la República, que nos llama al Gobierno de la nación, o el favorable a la monarquía, que obstinadamente, y contra la tradición verdaderamente española, nos ha mantenido alejadas de él»»20.

La cuarta conferencia, «Religión», versó sobre aspectos referidos a la libertad de cultos, la escuela laica y la separación entre Iglesia y Estado, y la postura de la

\footnotetext{
16 Idem, pp. 35 y 36.

17 Idem., pág. 57.

18 Idem., pp. 61-62.

19 Idem, pág. 88.

20 Idem., pp. 94-95.
} 
Iglesia católica hacia los mismos. En un tema tan delicado para la época y dada la influencia del pensamiento católico entre las españolas, María Lejárraga instaba a las mujeres a profundizar en la doctrina y no dejarse influenciar sin fundamento: «!Apasionadas católicas de España, seguidlo siendo, enhorabuena! Pero poned vuestra pasión en donde debe de estar: en la defensa del tesoro espiritual de la Iglesia» ${ }^{21}$. Finalizaba sus intervenciones con una conferencia con el título, «Federación", en el que ahondaba sobre las distintas formas de organización estatal de un país para seguidamente detenerse en el estatuto de Cataluña, intentando serenar el ambiente político creado: «no hay que asustarse en esta hora de formación ilusionada, ante el fantasma artificiosa y arteramente evocado del peligro catalán» ${ }^{22}$.

Concluía su cursillo especificando los aspectos que deseaba tuvieran en cuenta las mujeres al comenzar su trabajo de colaboración con la República:

«1. ${ }^{\circ}$ Desconfiad de las palabras; no os dejéis deslumbrar ni alucinar por lo que parece que quieren decir, y no las aceptéis ni las pronunciéis sin haber definido y decidido para vosotras mismas -y para los demás, si es posible- lo que realmente significan. $2 .^{\circ}$ Considerad que estamos en un momento de apasionada esperanza, pero también y sobre todo de seria responsabilidad. Preparaos con estudio y meditación a tomar vuestra parte en el trabajo necesario. 3. ${ }^{\circ}$ Debéis considerar la República no como un ideal alcanzado -lo cual sería sumamente cómodo, puesto que, llegados al fin del camino, ya no queda sino echarse a dormir - sino como un paso adelante en el camino de la libertad, aún no conseguida, sino atisbada. $4 .^{\circ}$ Debemos amparar al nuevo régimen por motivos esenciales e ideológicos (idea y esencia vienen a ser lo mismo) y por motivos de orden práctico. La realidad y el egoísmo se unen en este caso para marcarnos el rumbo a seguir. $5 .^{\circ}$ Entre los motivos más fuertes de nuestra adhesión está el que a la recién nacidad República le conviene librarnos de nuestra esclavitud legal y consagrar nuestra dignidad humana volviendo a nuestras manos la autoridad del matriarcado. 6. No hay que asustarse de fantasmas. Y especialmente de dos: la cuestión religiosa y la cuestión catalana, hábilmente suscitados, evocados, conjurados, creados o recalentados por los enemigos de la libertad ${ }^{23}$.

Por su parte, la intelectual y diputada en Cortes Margarita Nelken escribió en julio de 1931, vísperas de la aprobación de la Constitución, la obra «La mujer ante las Cortes Constituyentes» en la que manifestaba sus esperanzas en que la situación de las mujeres mejoraría con la nueva Constitución, y reflexionaba sobre lo que iban a suponer esos progresos. El interés de lo planteado en el ensayo para nuestro objeto de estudio hace obligado un breve análisis. La obra se estructura en cuatro capítulos, y la escritora comienza apelando al sacrificio de las españolas en aras del bien de España: «las mujeres españolas realmente amantes de la libertad, han de ser las primeras en posponer su interés propio al del progreso de España»24.

21 Idem., pág. 131.

22 Idem., pág. 162.

23 Idem., pp. 163 y 164.

24 NelKen, M.: La mujer ante las Cortes Constituyentes. Madrid, 1931, pág. 36. 
Los cuatro ejes temáticos en los que se articula su obra son los siguientes. En primer lugar, la concesión del voto a las mujeres. Su postura no era contraria pero consideraba que era algo que debía esperar pues debido a la falta de preparación y responsabilidad política de las mujeres podría resultar en «provecho y beneficio de los enemigos de la libertad». En su opinión: «Estamos, no lo olvidemos, en periodo de construcción (...) Precisamente porque la mujer ha de conseguir su ciudadanía con idénticos derechos que el hombre, no se le puede otorgar en un momento en que habría que significar un seguro, o simplemente un posible retroceso en el pleno disfrute de la ciudadanía para ambos sexos „25. En segundo lugar, defendía la aprobación de una ley de divorcio «que no puede ser ya objeto siquiera de discusión en la República», la investigación de la paternidad así como la eliminación de diferencias legales entre las madre casadas y solteras y la protección legal de estas últimas: «En la España de la Monarquía y del Concordato, el desamparo de la madre soltera y del hijo sin padre, podría explicarse; en la España de la República libre de trabas religiosas (...) toda desigualdad entre la madre casada y el hijo legítimo, y la madre soltera y el hijo nacido fuera de matrimonio, que no constituya una medida de protección a esta última, habrá de ser considerada como intolerable menosprecio a la naturaleza de la mujer ${ }^{26}$. En tercer lugar, apelaba a la aprobación de una legislación obrera femenina que mejorara la entonces vigente, y por último a la abolición de la prostitución reglamentada: "si la Constitución de la República, ha de reconocer realmente la identidad ciudadana de ambos sexos, no puede, ni tolerar un solo día la subsistencia de la prostitución reglamentada ${ }^{27}$.

Igualmente interesante es la labor de difusión realizada por las mujeres políticas a través de mítines. María Lejárraga recuerda lo ocurrido en un mitin en la Casa del Pueblo de Alfacar (Granada) durante la campaña electoral de las elecciones de 1933. Su discurso iba dirigido principalmente a las mujeres pero para su gran sorpresa a su llegada no encontró a ninguna, pues según le dijeron algunos varones presentes sentían temor o cierta desconfianza. Finalmente consiguió que un grupo muy reducido de mujeres acudieran. Su testimonio nos aproxima a la realidad de la época, los temores de muchas mujeres a participar en actividades políticas, así como el atraso cultural de determinadas regiones de la España de los años treinta: "Así tranquilizándolas como a chiquillos temerosos, conseguí — no eran mas de dos docenas-que se sentaran en las tres primeras filas de los bancos. Y pudimos hablar ... de tantas cosas. Del gran paso que daba la República fiándose de sus mujeres, de lo que debíamos agradecer la confianza que en nosotros ponían los hombres que querían hacer una España nueva, es decir, acabar en España con los dos males que la tenían atrasada y triste: el hambre y la ignorancia»,28.

25 Idem., pp. 35 y 34 .

26 Idem., pág. 65.

27 Idem., pág. 103.

28 Martínez Sierra, M.: Una mujer por los caminos de España. Recuerdos de propagandista. Buenos Aires, Ed. Losada, 1952, pág. 85. 
Como hemos visto a través del testimonio de las mujeres republicanas, muchas eran las mejoras sociales y jurídicas que las mujeres necesitaban y esperaban alcanzar durante la República. Algunas de esas reivindicaciones ya habían sido planteadas en décadas anteriores como por ejemplo por Carmen de Burgos quien defendía la igualdad jurídica, la aprobación de una ley de divorcio, la mejora de la educación de la mujer, así como su derecho al voto. Su pensamiento al respecto quedó magistralmente reflejado en su obra La mujer moderna y sus derechos, publicada en 1927. Pero de todas esas propuestas las más tratadas y difundidas fueron el divorcio y el voto. Así, por ejemplo, lo manifestaba Ignacia Olivarria en varios artículos de la revista Mujer en septiembre de 1931, señalando además la conveniencia para la República de aprobarlo: «El voto y el divorcio son las dos grandes necesidades de la mujer española; las ineludibles necesidades, no sólo para su mejoramiento moral y material, sino para un más amplio resurgir de nuestros pueblos. Cuando la mujer tenga entrada en la actuación pública española, cuando pueda aportar a ella sus actividades, tan interesantes, y junto a ellas sus sentimientos, tan sutiles, la vida material de la nación cambiará de rumbos (...) La nueva república española no podrá llamarse "democrática», si no se aceptan ambos derechos de la mujer»29.

La concesión del voto a las mujeres era crucial para un reconocimiento pleno de los derechos de las mujeres como ciudadanas, pero su falta de preparación y la posible influencia que el sacerdote o el marido pudiera ejercer sobre ellas alertaba a algunas de estas mujeres republicanas al considerarlo perjudicial para la República. Carmen de Burgos se manifestaba partidaria de la concesión y señalaba que «no vasta con ser elegibles, hemos de ser electoras» ${ }^{30}$. En esa línea hay que situar el pensamiento y actuación de Clara Campoamor, adalid del voto femenino en España, quien defendió el derecho al sufragio para la mujer en coherencia a su pensamiento político republicano: «Mi pensamiento era más político y nacional, más amplio y objetivo que el concreto feminista. Consideraba fatal para un resurgimiento de la libertad y la justicia que veía en la República, el divorcio espiritual de hombres y mujeres en España (...) consciente de mi derecho, de mi criterio y de mi conducta, como mujer, como ciudadana y como entusiasta de una República liberal y democrática»"31. Por su parte, la diputada Victoria Kent era contraria por razones de oportunidad política y así lo expuso en su intervención ante las Cortes: «no es cuestión de capacidad; es cuestión de oportunidad para la República. Por esto pido el aplazamiento del voto femenino o su condicionalidad; pero si condicionamos el voto de la mujer, quizá pudiéramos cometer alguna injusticia. Si aplazamos el voto femenino, no cometemos injusticia alguna, a mi juicio. Entiendo que la mujer, para encariñarse a un ideal, necesita algún tiempo de convivencia

29 OlivarRIA, I.: «Del momento. Una grata esperanza, pero...». Mujer, 12 de septiembre de 1931, n. ${ }^{\circ}$ 15, pág. 1.

30 Olmo, R.: «La mujer en la política. Carmen de Burgos». Mujer, 27 de junio de 1931, n. ${ }^{\circ} 4$, p. 6.

31 Campoamor, C.: Mi pecado mortal. El voto femenino y yo. Sevilla, Instituto Andaluz de la Mujer, 2001, pp. 21 y 201. 
con el mismo ideal. La mujer no se lanza a las cuestiones que no ve claras y por esto entiendo que son necesarios algunos años de convivencia con la República; que vean las mujeres que la República ha traído a España lo que no trajo la Monarquía»32.

La concesión del voto a las mujeres fue muy criticado desde diversos sectores políticos, especialmente de izquierdas, por considerar que sería pernicioso para la República: "La República ha sufrido un daño enorme, y sus resultados se verán muy pronto»33. Sin embargo, la opinión de muchas mujeres y asociaciones femeninas era muy distinta. En la revista Mujer queda reflejado en diversos artículos el entusiasmo por los logros conseguidos: "celebremos el triunfo, el triunfo de todos y sobre todo el de España (...) la mujer española debe sentirse orgullosa de sus conquistas actuales (...) La República gran amiga de la mujer ha puesto en trance de volar a todo el que tenga alas». Igualmente se instaba a las mujeres a seguir colaborando con la República para que no se perdieran los logros alcanzados: "Una vez conseguidos los amplios derechos que el nuevo régimen nos ha otorgado, es nuestro deber, el más ineludible, laborar para que no nos sean rectificados aquéllos» ${ }^{34}$

\section{LA I/ REPÚBLICA Y LAS MUJERES:}

La década de los años 30 se presenta paradójicamente para las mujeres españolas como el periodo histórico en el que se producen avances y retrocesos muy acusados en su situación jurídica y social. En una sociedad y una legislación tradicionalmente desigualitaria hacia las mujeres como es la española, la llegada de la II República en 1931 abrió la posibilidad de llevar a cabo una reforma legislativa y social favorable hacia las mujeres, a todas luces justa y necesaria.

Las propias características del régimen, la voluntad de unas elites gubernamentales, la adecuación a los nuevos tiempos, la presencia y participación activa de mujeres en el ámbito público, como hemos señalado en páginas anteriores, contribuyeron a que la legislación republicana recogiera principios igualitarios. En el artículo 2 de la Constitución de 1931, Carta Magna del régimen republicano, se establecía la igualdad de todos los españoles ante la Ley: «Todos los españoles son iguales ante la ley». Este precepto no tenía un carácter innovador, pues ya había quedado recogido en otros textos Constitucionales anteriores, y a pesar de su aparente igualdad, encerraba diferencias entre los derechos de los sexos. Sin embargo, en la Constitución republicana se establecían una serie de principios legislativos que puntualizaban las igualdades jurídicas entre los dos sexos. Si-

32 Diario de Sesiones. Legislatura 1931, p. 1351

33 La Voz, 1 de octubre de 1931.

34 Olivarría, I.: «Del momento. Más actuaciones femeninas». Mujer, 21 de noviembre de 1931, n. 23, p. 1; «Del momento. El voto femenino». Mujer, 10 de octubre de 1931, n. ${ }^{19}$, pág. 1; «Del momento. El divorcio aprobado». Mujer, 24 de octubre de 1931, n. ${ }^{\circ}$, pág. 1. 
guiendo este espíritu, en el artículo 25 se especificaba la prohibición de privilegio jurídico por «la naturaleza, la filiación, el sexo, la clase social, la riqueza, las ideas políticas ni las creencias religiosas».

En la esfera de los derechos políticos, la incorporación de las mujeres a la política activa fue uno de los mayores logros del nuevo régimen, siendo fruto, también, del largo proceso iniciado años atrás con el ingreso creciente de mujeres en el ámbito público. Sus derechos quedaban recogidos en los artículos 36 y 53 de la Constitución, los cuales reconocían, respectivamente, sus derechos electorales y poder ser diputada elegible. La única limitación en este sentido quedaba en no poder aspirar a la presidencia del gobierno (artículo 69) ${ }^{35}$. Estas medidas fueron muy importantes ya que por primera vez, las mujeres españolas accedían a un ámbito hasta entonces prohibido, y sumamente conveniente pues, como señala la escritora Carmen de Burgos (Colombine), las mujeres con un nivel de formación se habían dado cuenta que «la papeleta de voto es un arma y que si no tienen el derecho al sufragio no obtendrán fácilmente de los Parlamentos las reformas que solicitan» ${ }^{36}$.

En la esfera de lo privado, el artículo 43 de la Constitución señalaba la igualdad de derechos de ambos sexos en el matrimonio, así como la disolución del mismo a petición de cualquiera de los cónyuges alegando causa justa: «La familia está bajo la salvaguardia especial del Estado. El matrimonio se funda en la igualdad de derechos para ambos sexos, y podrá disolverse por mutuo disenso o a petición de cualquiera de los cónyuges con alegación en este caso de justa causa». En 1932 se promulgó la Ley de divorcio que aún con los fallos jurídicos que encerraba y la polémica que suscitó, vino a mejorar la condición jurídica de la mujer en caso de crisis matrimonial. De esta forma se sustituyó nominalmente la "casa del marido» por el «domicilio conyugal», se suprimió el "depósito» de la mujer casada, y se permitió a la mujer bínuba conservar la patria potestad de los hijos habidos en el primer matrimonio ${ }^{37}$. Por el contrario, se seguía exigiendo al juez que señalase domicilio para la mujer como medida provisional durante los trámites de separación, había limitaciones en cuanto a la administración de los bienes de la sociedad conyugal, y al cónyuge culpable se le negó el derecho a alimentos, medida esta última muy perjudicial para las mujeres que no contaban con patrimonio personal ni ingresos profesionales extradomésticos. Durante 1932 y 1933 un $56 \%$ de las demandas de divorcio presentadas fueron realizadas por mujeres, frente al $43 \%$ de los varones. Entre las causas principales se encontraban la separación por más de tres años, el desamparo, el abandono, los malos tratos y la

35 La ley electoral de 27 de junio de 1933 concretaba estos derechos al declarar el derecho de todos los ciudadanos mayores de 23 años a elegir y ser elegidos sin hacer distinción por motivo de sexo o estado civil.

36 Burgos, C.: La mujer moderna y sus derechos. Segovia, 1927, pp. 264-265.

37 Esta medida se basaba, además del artículo 21 de la Ley de divorcio, en los artículos 25 y 43 de la Constitución y en la Resolución de 4 de octubre de 1933 de la Dirección General de Registros, con lo que quedaba derogado el artículo 168 del Código Civil. 
conducta inmoral ${ }^{38}$. En esta línea reformista, se establecía la igualdad entre los hijos legítimos e ilegítimos, la investigación de la paternidad y el matrimonio civil (Ley de 28 de junio de 1932), ley que junto con la del divorcio fue el objetivo de las críticas de los sectores más conservadores de la sociedad, ya que a su entender suponían un peligro para la estabilidad de la familia y la sociedad.

En el ámbito profesional, el artículo 40 de la Constitución aseguraba su legítimo derecho a ejercer una profesión. Los debates entre los defensores y los detractores de la incorporación de las mujeres al mundo laboral extra doméstico fueron numerosos. Se aducían razones biológicas, obligaciones familiares -atención al marido y a los hijos-, y por parte de los sectores más progresistas cierto temor a las consecuencias sociales y económicas que la posible incorporación masiva podía tener en la joven República, máxime en una época de crisis económica como era la de los años treinta. Sin embargo, poco a poco se fueron abriendo a las mujeres empleos públicos tradicionalmente ocupados por varones como notarías y registros de la propiedad, cuerpo diplomático, secretarios municipales, y procurador en los Tribunales. Además se crearon cuerpos femeninos en algunos ministerios: Cuerpo de Auxiliares Femeninos de Correos, Cuarta Sección del Cuerpo Auxiliar Subalterno del Ejército; Sección Femenina Auxiliar del Cuerpo de Prisiones, Mecanógrafas del Ministerio de la Marina, y Cuerpo de la Escala de Telegrafistas Femeninos. Sin embargo, y basándose en la limitación establecida en el artículo 40 de la Constitución —»Todos los españoles, sin distinción de sexo, son admisibles a los empleos y cargos públicos según su mérito y capacidad, salvo las incompatibilidades que las leyes señalen»-, siguieron cerradas algunas profesiones como Fuerzas Armadas, carrera fiscal, judicial y Secretarios Judiciales, cuerpos ministeriales, y el cuerpo pericial de aduanas.

La legislación laboral referida a las mujeres, de claro carácter protector, siguió vigente aprobándose nuevas normativas que venían a reforzarla, concretamente los decretos dirigidos a apoyar en sus puestos de trabajo a las madres y a las mujeres casadas, así como el seguro de maternidad. No obstante, esta legislación aún encerraba desigualdades, y seguía limitando a la mujer casada el disfrute de su trabajo, como quedaba recogido en la Ley de 21 de noviembre de 1931 y el Código de trabajo de 1926, tales como ser el marido el representante legal de la mujer, para contratar empleo, o el derecho de la mujer a percibir su sueldo, siempre y cuando no se opusiera el marido.

Respecto al Código Penal (27 de octubre de 1932), se suprimió el delito de adulterio en la mujer y el amancebamiento en el varón. A partir de ese momento, ya no se reconocía el derecho del marido para matar a los adúlteros ni el del padre para matar a su hija y corruptor. La eliminación partió de una enmienda presenta-

38 Estadísticas de divorcios y separaciones. Madrid; Ministerio de Justicia, 1936. Vid. MoRCILLo GóMEZ, A.:»Feminismo y lucha política durante la II República y la Guerra Civil», en FolguERA, P. (Comp.). El feminismo en España: dos siglos de Historia. Madrid, Ed. Pablo Iglesias, 1988, pp. 68-69. 
da por Clara Campoamor. En otro orden de cosas, se les permitió ser miembros de los jurados penales, en igual proporción que los varones, si bien restringido a las causas sobre crímenes pasionales ${ }^{39}$. A través de la Ley de asociaciones profesionales de patronos y obreros (Ley de 8 de abril de 1932) se permitió a la mujer casada pertenecer a las asociaciones obreras sin necesidad de licencia del marido, si bien quedaba aún excluida de las de patronos o algunas de carácter más filantrópico como la Cruz Roja.

En la esfera social y moral se abordó uno de los temas más delicados. La prostitución no afectaba social y moralmente sólo a las mujeres, sino también a la sociedad de esa época caracterizada por una doble moral sexual ${ }^{40}$. Pero pocos se atrevían a tratarla profundamente y buscar soluciones. Durante los primeros años de la II República se aprobaron distintos decretos para proteger la situación de las mujeres que se movían en ese ambiente; nos referimos al Decreto de 1 de junio de 1931 que suprimió el Real Patronato para la Represión de la Trata de Blancas o el Decreto de 11 de septiembre de 1931 por el que se creó el Patronato de Protección a la Mujer. Pero dichas medidas, años más tarde, coincidiendo con el bienio negro se fueron derogando. El Decreto de 25 de junio de 1935 disolvía el Patronato de Protección a la Mujer, delegando sus funciones al Consejo Superior de Protección a la Infancia, y el Decreto de 28 de junio suprimía la reglamentación de la prostitución anulándola como medio lícito de vida.

Finalmente debemos destacar los logros legales aprobados por el Parlamento de Cataluña. En el año 1931 se autorizaba la creación del Instituto-Escuela en Barcelona, en el que se admitieron alumnos de los dos sexos y en donde se ponía en funcionamiento la coeducación. También se reconocía la igualdad de derechos entre hombre y mujer, estableciendo que el matrimonio se fundamentaba en la igualdad de derechos de los cónyuges, y se aprobaba la Ley sobre la capacidad jurídica de la mujer y los cónyuges de 13 de junio de 1934 por la que se suprimía la necesidad de licencia.

A la luz de todo lo dicho, se puede pensar que la situación jurídica de las mujeres mejoró considerablemente durante el período republicano. Cierto es que no todo quedó solucionado y ello fue debido a dos razones, principalmente: la brevedad del régimen, que impidió materializar en leyes muchos de los principios expresados en la Constitución, y el peso de la tradición que hacía palpable la idea de que la igualdad ante la ley no era la igualdad ante la vida: «Mucho esperaba la mu-

39 Ello fue a través del decreto-ley de 27 de abril de 1931, que reinstauró y modificó la ley de jurados populares en los tribunales de Justicia de 20 de abril de 1888, derogada durante la dictadura de Primo de Rivera. Se permitió a las mujeres a partir del 1 de septiembre de 1931. Vid. BOATWRIGHT, M. y UCELAY DA CAL, E.: «El otro «jurado mixto»: la introducción de la mujer en los tribunales para crímenes pasionales en la II República». Ordenamiento jurídico y realidad social de las mujeres: siglos XVI a XX. Actas de las IV Jornadas de Investigación Interdisciplinaria. Madrid, Seminario de Estudios de la Mujer de la UAM, 1986, pp. 377-390.

40 LIDÓN, J.M.a: «La reglamentación de la prostitución en España durante los siglos XIX y XX». Estudios de Deusto, 30, 69, pp. 407-493. 
jer del Gobierno republicano, aunque las dificultades eran manifiestas, pues el ser republicano no quería decir ser feminista" ${ }^{41}$. No obstante, el balance no puede resultar negativo ya que las mujeres españolas alcanzaron derechos y cotas de presencia y participación en la vida social y política no logradas hasta entonces. Como señala Esperanza García Méndez, la equiparación legal era el primer paso, era de vital importancia, "ya que crea las condiciones favorables para lograr la liberación femenina en otros terrenos»?

\section{5. «MÁS ALLÁ DE SU ÉPOCA, MÁS ALLÁ DE LOS TIEMPOS»: UNAS BREVES CONCLUSIONES}

A lo largo del presente estudio hemos profundizado en las mujeres con ideario republicano, su visión de la República, su perspectiva de la misma como mujeres, así como los logros alcanzados durante el régimen republicano desde una perspectiva de género. Pero estas mujeres no sólo contribuyeron con su pensamiento y actividad profesional a hacer una realidad el proyecto republicano. No, su coherencia ideológica y vital, ha traspasado tiempos y fronteras. Carmen de Burgos falleció el 9 de octubre de 1932 tras una conferencia en el Círculo Radical Socialista, pronunciando: «imuero contenta porque muero republicana»", pero el resto de las mujeres republicanas estudiadas en este trabajo iniciaron un largo exilio que en muchas ocasiones no las permitió regresar a España. Todas ellas reflexionaron en diversos escritos sobre los años de la II República, los logros alcanzados, las dificultades con las que se tuvo que trabajar. En su discurso en la entrega del Premio Cervantes en 1988, María Zambrano reflexionaba sobre el fracaso de la II República y señalaba: «la que forzosamente tuvo que fracasar, porque había ido más allá de su época, más allá de los tiempos. Y es que posee la historia un ritmo inexorable que condena al fracaso a todo aquello que se le adelanta o que le desborda "44. Confiemos en que este juicio no se haga extensible a las mujeres objeto de nuestro estudio.

41 TElo NúÑEZ, María. La evolución de la mujer española en el campo jurídico. Análisis e investigaciones culturales, 11, 1982, pág. 69.

42 Garcia Mendez, Esperanza. La actuación de la mujer en las Cortes de la II República. Madrid; Ministerio de Cultura, 1979, pág. 29.

43 Bravo Cela, B. Carmen de Burgos (Colombine). Contra el silencio. Madrid, Espasa, 2003, pág. 213.

44 Discurso de María Zambrano en la entrega del Premio Cervantes en 1988. Vid. Zambrano, M. Delirio y Destino (los veinte años de una española). Barcelona, Mondadori España, 1989, pág. 332. 